\title{
Anxious and depressed women's experiences of emotional suffering and help seeking in a Rio de Janeiro favela
}

\author{
Experiências de mulheres ansiosas e deprimidas sobre sofrimento \\ emocional e busca de cuidado em uma favela do Rio de Janeiro
}

Karen Athié ${ }^{1}$

Christopher Dowrick ${ }^{2}$

Alice Lopes do Amaral Menezes ${ }^{1}$

Luanda Cruz ${ }^{1}$

Ana Cristina Lima ${ }^{1}$

Pedro Gabriel Godinho Delgado ${ }^{3}$

Cesar Favoretto ${ }^{1}$

Sandra Fortes ${ }^{1}$

\footnotetext{
${ }^{1}$ Laboratório

Interdisciplinar de Pesquisa em Atenção Primária à Saúde, Pós-Graduação em Ciências Médicas,

Universidade do Estado do Rio de Janeiro. Boulevard Vinte e Oito de Setembro 77, Vila Isabel. 20551-030 Rio de Janeiro RJ Brasil. karensathie@gmail.com ${ }^{2}$ Institute of Psychology Health and Society, University of Liverpool. Liverpool Inglaterra. ${ }^{3}$ Núcleo de Políticas Públicas em Saúde Mental (NUPPSAM), Universidade Federal do Rio de Janeiro. Rio de Janeiro RJ Brasil.
}

\begin{abstract}
Taking into consideration issues such as stigma and the mental health gap, this study explores narratives of anxious and depressed women treated in a community-based primary care service in a Rio de Janeiro favela about their suffering and care. We analysed 13 in-depth interviews using questions from Kadam's study. Framework analysis studied Access, Gateway, Trust, Psychosocial Issues, and Primary Mental Health Care, as key-concepts. Vulnerability and accessibility were the theoretical references. Thematic analysis found "suffering category", highlighting family and community problems, and "help seeking category", indicating how these women have coped with their emotional problems and addressed their needs through health services, community resources and self-help. Women's language patterns indicated links between implicit social rules and constraints to talk about suffering, especially if related to local violence. High medical turnover and overload are barriers for establishing a positive relationship with family physicians and continuity of care is a facilitator that promotes trust, security and adherence. Concluding, to plan community-based primary mental health care of this population, cultural and social factors must be comprehended as well as the work health teams conditions.
\end{abstract}

Key words Mental health, Primary care, Depression, Anxiety, Access
Resumo Considerando o estigma e a lacuna de acesso ao cuidado em saúde mental, o estudo explorou narrativas de mulheres ansiosas e deprimidas, atendidas na Clínica da Família em favela do Rio de Janeiro, sobre sofrimento e cuidado. Analisou-se 13 entrevistas em profundidade a partir das perguntas do estudo de Kadam. Os dados foram dispostos em Framework, tendo Acesso, Porta de Entrada, Confiança, Questões Psicossociais e Saúde Mental na Atenção Primária como conceitos norteadores. Vulnerabilidade e acessibilidade embasaram teoricamente essa leitura. Do estudo temático emergiram as categorias: "sofrimento emocional" onde se destacam os problemas familiares e comunitários e "busca de ajuda" revelando o papel dos serviços de saúde, recursos comunitários e a autoajuda no enfrentamento do sofrimento emocional. Regras sociais implícitas constrangem as mulheres. sendo observados padrões de linguagem específicos ligados à vulnerabilidade è à violência. Alta rotatividade e sobrecarga dos profissionais são barreiras para uma relação positiva com essas mulheres ao passo que a continuidade do cuidado é facilitador da confiança no profissional, gerando segurança e adesão. Conclui-se ser crucial considerar fatores socioculturais e condições adequadas de trabalho das equipes para o cuidado integral dessa população.

Palavras-chave Saúde mental, Atenção primária, Depressão, Ansiedade, Acesso 


\section{Introduction}

The care of people with anxiety and depression involves aspects ranging from stigma ${ }^{1}$, acceptance of the illness ${ }^{2}$ and clinical management ${ }^{3}$. Disregarding these circumstances might affect patients' quality of life $\mathrm{f}^{4}$ and worsen the prognosis of chronic physical diseases ${ }^{5}$. Common mental disorders (CMD) are also strongly associated with gender issues and social inequity ${ }^{6,7}$. Their prevalence is extremely high among patients attending primary care, currently been regarded as epidemic ${ }^{8}$. Taking care of $\mathrm{CMD}^{9}$ has been considered a challenge to public health systems, particularly to integration of mental health care actions in primary care setting.

The Global Mental Health Movement calls for action to reduce the gap between health needs and care provision ${ }^{10}$ suggesting community-based services. In order to guarantee treatment of adult patients with CMD, although primary care and mental health integration has been considered a complex process of work ${ }^{11}$, implementing collaborative actions is recommended, specially in Low and Middle Income Countries (LAMIC) $)^{12-14}$. The aim is to improve primary mental health care access in a vulnerable population through collaborative care ${ }^{15}$, professional's training and organisation of multidisciplinary teams with non mental health specialists, such as community health workers $(\mathrm{CHW})^{16}$ and counsellors ${ }^{17}$.

Little is known about patients' experiences in this setting. The literature on experiences of patients diagnosed with CMD in community-based primary care services demonstrates challenges such as health professionals' communication abilities about the emotional suffering ${ }^{18}$ and continuity of care $^{19}$; psychosocial interventions tailored to primary care setting in different cultural contexts ${ }^{20,21}$; and the relationship between patients, services and primary mental health care ${ }^{22,23}$.

Bearing in mind the WHO Mental Health Gap discussion ${ }^{24}$, this study tackled to emphasise patient's experiences of mental health suffering ${ }^{25}$ in a vulnerable ${ }^{26}$ and unequal ${ }^{27}$ context where primary mental health care have been set $u^{28}$.

This model of work was implemented in a violent Rio de Janeiro favela called Morro dos Macacos. The community-based primary care service is called Family Health Strategy (FHS). Particularly in Rio de Janeiro, this offer has grown, between 2008 and 2013, increasing coverage by FHS unities from $3 \%$ to $48 \%$ of the population prioritizing low-income areas ${ }^{29}$.
The FHS unities can have one or more FHS teams. Each team has a family doctor (FD), a nurse, a technical nurse and $6 \mathrm{CHW}$ delivering care to 3500 people. As tenets they work with an enrolled population, continuity of care and active search.

The collaborative mental health team is called Mental Health Matrix Support (MHMS). Created to collaborate with FHS, to improve access and their FHS team's skills to deal with mental health problems, this integrative care model has been implemented in more than 5000 Brazilian cities $^{30}$. The MHMS team have a psychiatrist and a psychologist collaborating through actions such as joint consultation, domiciliary visits and groups.

Hence, this qualitative case study is about anxious and depressed women experiences with access to primary mental health care and how they have been dealing their suffering in Rio de Janeiro's favela.

The research was in a vulnerable community with a low-income population and constant violence. In this regard, the theoretical concepts used were vulnerability and accessibility.

Malagon-Oviedo and Czeresnia ${ }^{31}$ consider vulnerability not only as an instability between a human being and a challenge of the environment, but also a concept that links a vulnerable person and a coercive situation, a relationship established between oppressor and oppressed. We also consider the perspective of vulnerability of people living in a community as a group with similar problems, as suggested Campbell et al.

Firstly, to comprehend the health care perspectives of women living in a Rio's favela, accessibility was the second theoretical reference employed. This concept is related to enabling a population to engage with a community-based service. In this case, as suggested by Hall et al. ${ }^{32}$, trust arising from vulnerable conditions is helpful to understand the link between patients' needs and FHS services. Due to the fact that the group studied has CMD, mental health stigma ${ }^{33}$ and difficulties to accept mental health as a health problem were embedded in these references. Secondly rather than to install a community centre in a vulnerable community, which does not seem enough to a vulnerable population to trust ${ }^{34}$, the literature recommends identifying stakeholders to create service linked to the local people $e^{35,36}$. Hence, access to mental health care in a community-based service is a bridge linking the service and community, containing clinical, social, cultural and political elements. 
The purposes of this study were to explore the issues:

1. Anxious and depressed women from a Rio's favela requirements to talk about their suffering

2. How they have been experiencing care offered by FD in FHS and MHMS team in primary care setting.

\section{Method}

\section{Qualitative Design}

This qualitative case study was designed to explore anxious and depressed women's narratives about suffering and help-seeking, including primary care services with mental health collaborative care teams, in one Rio's favela. In order to identify their experiences about that, we tackled 3 main issues:

- Links between their emotional suffering and their local context

- Sources of community-based care.

- Lessons provided by these narratives for the organization of community-based primary mental health care.

\section{Area}

The area is a Rio's favela (slum) called Morro dos Macacos located in Vila Isabel neighbourhood, which have a contrasting Social Development Index(SDI). While Morro dos Macacos has 0.55 (low SDI), Vila Isabel has 0.67 (medium SDI). Using another index (Human Development Index) Vila Isabel in general is considered high (0.9), the same level of Rio de Janeiro city as a whole (0.799). These indexes highlighted social and economical diversity in a metropolis like Rio de Janeiro.

\section{Setting}

Since 2006, the Morro dos Macacos has a FHS Unit named Parque Vila Isabel. This unit has 3 teams covering this area.

In 2008 MHMS actions started in this favela aiming to help FHS teams to improve access to mental health through regular meetings once a month. Women handcraft support's group was also developed by the collaboration between FHS and the MHMS as an intervention for patients with emotional suffering, including CMD. The activity has been leaded by CHWs and helped by a psychologist-facilitator from the MHMS team.

\section{Participants}

The group studied were women (18 to 80 years old) who was diagnosed with CMD in a previous study: Evaluation of Depression treatment in Primary Care in Programmatic Area 2.2 in Rio de Janeiro, Brazil, 2011, or in the selection for the women groups.

In 2013, 69 positive patients from this first study were contacted. Only 22 initially accepted to participate. The low return rate was due to wrong phones numbers for contact and the time the interviews were scheduled due to the unit's working hours. Women employed or not available on business hour (9 AM to 5 PM) had more difficulties to participate. Due to lack of trust in the Unit two contacts refused to participate. People in treatment in specialised units with psychologists or psychiatrists were excluded. Ten were interviewed.

Using the saturation criteria the research team decided to invite other diagnosed patients from women group (Women of Programmatic Area 2.2 Project: income generation and social support groups as a strategy to care for patients with CMD in FHS Unities). They were diagnosed with CMD, lived in the same favela and were treated in the same unit. One of the interviewees was in both projects.

There were no sociodemographic or medical differences between these two groups (Table 1). A total of thirteen were interviewed. To preserve their identity, all real names were shift to flower's names (Rose, Heather, Tulip, Marigold, Daisy, Orchid, Violet, Angelica, Lily, Jasmine, Acacia, Palm, Pansy).

\section{Tools}

The tool used was a semi-structured in-depth interview covering 6 topics developed in a qualitative study about patients' views on anxiety and depression published by Kadam et al. (Chart 1). The questions were about: emotional suffering experiences and how women used to find help as well as what they expected, including their help-seeking experiences, with general practitioners. The questions were translated to Portuguese ${ }^{37}$. The data collection was recorded and transcribed.

\section{Analyses}

A framework ${ }^{38}$ was created for analyzing the data using key-issues based in primary mental health care dimensions previously discussed in 
Table 1. Women's Group Profile. Anxious and Depressed Women’ Sample.

\begin{tabular}{|c|c|c|}
\hline Age & 30 to 77 age & 58 mean \\
\hline Personal Income & 0 to USD 263.71 & USD 134,36 monthly mean \\
\hline Folk & $\begin{array}{l}\text { The most of them were brown or mulatto, } \\
\text { followed by black and white. }\end{array}$ & \\
\hline Familiar Status & $\begin{array}{l}2 \text { never married or lived with someone } \\
6 \text { married or had an union } \\
3 \text { divorced } \\
1 \text { widow }\end{array}$ & \\
\hline Professional Status & $\begin{array}{l}\text { housewives, housemaids, retired, unemployed, } \\
\text { saleslady or administrative assistant }\end{array}$ & \\
\hline Educational Level & $\begin{array}{l}7 \text { went to the school for } 8 \text { years, } \\
3 \text { went to the school for } 4 \text { years } \\
3 \text { went to the school between } 8 \text { and } 12 \text { years and }\end{array}$ & \\
\hline Religion & $\begin{array}{l}5 \text { Catholics } \\
4 \text { Protestants } \\
1 \text { Umbanda/ Afro-Brazilian Religion }\end{array}$ & \\
\hline
\end{tabular}

Chart 1. In-Depth Interviews Script from Kadam et al. ${ }^{37}$. A Qualitative Study of Patients' Views on Anxiety and Depression. British Journal of General Practice, 2001. In-Depth Interviews Script.

1. If you can think of an occasion when you have felt 'stressed', please tell the 'story' of what happened what lead up to the problem, what you felt during this time and who or what was involved? The word 'stress' could mean feelings of tension, wound up, anxious or mood which was low, tearful, or depressed.

2. When you had this problem, how did you cope with it or what help did you seek?

3. What sort of things made the problem worse or were not of any help?

4. In an ideal world what sort of help should be available? Are there any new ways of coping with problems

that you have heard about and might want to try out, particularly in relation to the type of problem you

described on the previous page?

5. At the time of your own 'stress' how could your own General practice have possibly helped?

6 . Have you any comments or observations on this study?

another broad project about primary care and mental health integration in the MHMS perspective. Evaluation of Primary Care and Mental Health Integration in a Programmatic Area 2.2 in the city of Rio de Janeiro. In order to contrast and compare different perspectives about MHMS, this narrative study searched women's experiences about the same dimensions studied before: Access, Gateway, Trust, Psychosocial Problems, and Primary Mental Health Care (Chart 2).

Following, to interpret the data, interviews were listened to and read repeatedly. The ideas were noted down to develop initial codes ${ }^{39}$. Based on the dimensions showed, three researchers (a psychologist, a psychiatrist and a FD) analysed data. Although, there was no disagreement, it was observed that each one used their professional point of view in the analyses. For instance, the psychologist observed language patterns, the psychiatrist the relationship with the treatment offer and the FD why these women do not seek exclusively medical help for taking care of their emotional suffering.

After, the classification of the data was useful to tailor the narratives into the two emerged category: emotional suffering and help seeking (Figure1). Although primary mental health care community based in LAMIC has relevant references in the literature ${ }^{35,40}$, there is a gap about this subject in Brazil. Thus, the sub-categories, were developed inductively ${ }^{41}$ and fostered the answers to the 3 key-issues of this study. 


\section{Ethical Aspects}

The research protocol was approved by the University of the State of Rio de Janeiro and Rio de Janeiro's Municipal Secretary Ethics Research Committees. All women interviewed signed the consent form.

\section{Results and Discussion}

The results indicated barriers and facilitators to accept care and share suffering using three key-issues: links between emotional suffering and local context; sources of community-based care; and lessons provided by these narratives to primary mental health care.

Chart 2. Primary Mental Health Care Dimensions.

\begin{tabular}{|l|l|}
\hline \multicolumn{1}{|c|}{ Dimensions } & \\
\hline Access & How the patient sets a care appointment \\
\hline Gateway & How the patient describes the health service offered \\
\hline Trust & How the patient describes the continuity of care \\
\hline Psychosocial Problems & How the patient describes their suffering or from others \\
\hline Primary mental health care & How the patient describes solutions for their suffering in the community \\
\hline
\end{tabular}

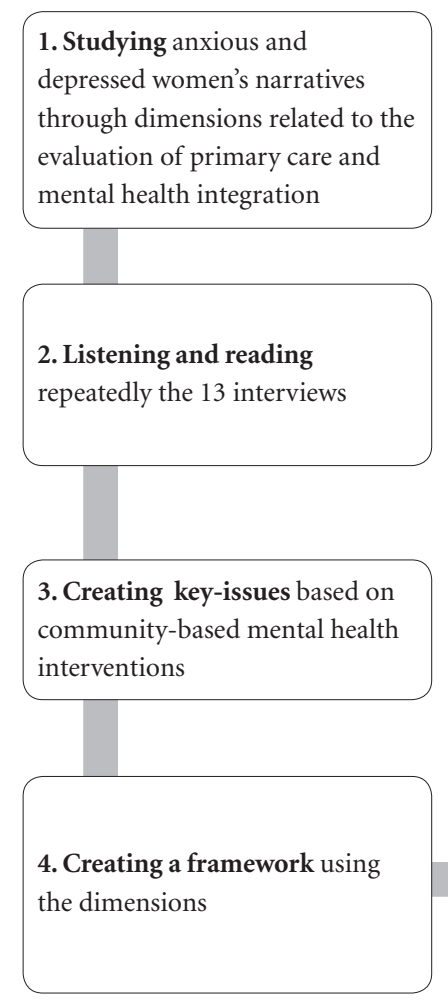

1. Studying anxious and depressed women's narratives evaluation of primary care and mental health integration

\section{Listening and reading} repeatedly the 13 interviews

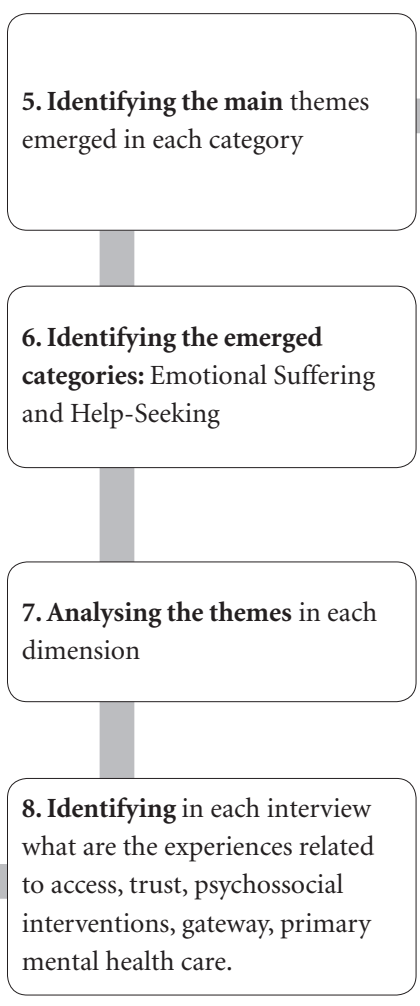

9. Creating each

sub-categories

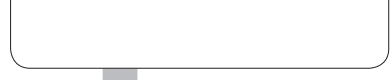

10. Analysing and identifying narratives patterns concerning theoretical references (accessibility and vulnerability

Figure 1. Analysis Process Workflow. 
Firstly, this discussion emphasised specific women narratives' patterns indicating how in this context they should express their emotional problems. Secondly, the Emotional Suffering and Help Seeking categories and their sub-categories (Chart 3) highlighted how local rules counteracts what they need to alleviate emotional suffering. Thirdly, the analysis indicated barriers and facilitators of the relationship established between these women's needs and the primary mental health care offered, by FDs in the FHS Unit (Chart 4).

\section{Women's Narratives Patterns}

Women narratives demonstrated language patterns, which seem to be a local speech, not only to express suffering and to talk about violence problems, but mainly a way to overcome favela's implicit rules of communication ${ }^{41}$. Turning to indirect ways of sharing their suffering experiences, women frequently demonstrated fear of expressing themselves freely. For instance, an interviewee said she believed there is a mutual pact between herself and FD because she noted when she did not allude to the favela's context, the FD did not question her either.

Yes, I do not tell anything to the doctor and he does not ask me either... do you know what I mean? (Tulip)

The expression "I do not tell anything" illustrated how the local rules determinates what can be communicated to people considered outsiders. This is a common way to express their worries, although the local relationships involving violence tends to impose silence of local violence. The narratives introduced the violence and other vulnerable situations discretely, which suggested that they have local secrets. Additionally, as they wanted to assure the interviewer's comprehension of this oxymoron, women often asked if the interviewer understood what she was communicating. This indicates that the narrative was constructed carefully evaluating what could be said or not, due to the consequences of community laws. Moreover, the rhetoric highlighted that they looked for complicity with the interviewers,

Chart 3. Summary of Categories.

\begin{tabular}{|c|c|}
\hline Emotional Suffering & Help Seeking \\
\hline $\begin{array}{c}\text { Individual problems } \\
\text { grief, physical symptoms (insomnia, headache, vomit, } \\
\text { sadness, }\end{array}$ & $\begin{array}{c}\text { Health services } \\
\text { in community (FHS) } \\
\text { Family problems } \\
\begin{array}{c}\text { lack of family support, awareness with grandsons, } \\
\text { domestic violence, traumatic familiar scenes. }\end{array}\end{array}$ \\
$\begin{array}{c}\text { Community Problems } \\
\text { violence }\end{array}$ & $\begin{array}{c}\text { Community solutions } \\
\text { drug dealers (internal slum rules) } \\
\text { institutional religious }\end{array}$ \\
& $\begin{array}{c}\text { Self- help } \\
\text { contact with nature } \\
\text { positive thoughts }\end{array}$ \\
\hline
\end{tabular}

Chart 4. What is important to anxious and depressed women share their emotional problems with Family Doctors in a favela (slum)?

\begin{tabular}{|c|c|}
\hline Barriers & Facilitators \\
\hline 1. Doctor is someone from outside & 1. Trust \\
\hline 2. Length of consultations and overload, turnover & 2. Community health worker \\
\hline 3. Afraid of gossip and lack of secrecy & 3. Family doctor permanence \\
\hline 4. Do not know that they can share emotional problems & 4. Medication \\
\hline 5. To believe that it is better to share with an specialist & 5. Co-morbidities \\
\hline $\begin{array}{l}\text { 6. To believe that a family doctor do not treat mental } \\
\text { health issues }\end{array}$ & $\begin{array}{l}\text { 6. Opportunity to talk in security: Group activities, } \\
\text { mental health professionals in community }\end{array}$ \\
\hline
\end{tabular}


mainly when asking for acquiescence instead of accurately affirming their thoughts.

Sometimes, another language pattern arises when they express directly their emotional suffering experience related to being powerless, particularly when they are unable to protect their families of local violence. For instance:

Violence, because I ... Many times I came here bringing my grandson to school while there was shooting, my legs were locked, my grandchildren could not enter in the Community, many times I could not even seek my granddaughter at school, because there was a lot of shooting. (Daisy)

As a whole, the analysis of these situations indicates women's resilience in a hostile environment, which may underline personal sources of empowerment as developing ways to be adapted in coercive situations ${ }^{28}$. It also demonstrates how they cope with their suffering under these local rules $^{42}$.

Due to these people's perspective based on theirs sense of geographical and historical place, their different roles, they are able to adapt and create new meanings for their problems. Resilience, as a key to investigate these reactions, might be understood as an exercise of ingenuity and imagination, as Dowrick et al..$^{28}$ pointed out from learning the art of living intelligently with misunderstanding. This author defined resilience actions in vulnerable situations as an effect of personal support networks and resources to deal with problems, as well as a natural reaction to survive, tackling particular activities, expanding meaning, emotions and strengths.

Thus, narratives evidenced language patterns that reflect the local rules while women were coping with emotional suffering in favela. Silence, fear and indirect ways to describe causes and consequences of that were commonly related to their vulnerable situation.

Hence, although this underlined useful abilities to live in an adverse context, the language patterns indicated the powerless conditions of these women ${ }^{20}$.

\section{Emotional Suffering and Help Seeking Categories}

\section{Emotional Suffering Categories}

The narratives presented 3 different subcategories: individual problems, family problems and community problems. Individual problems were linked with physical problems, either as a cause or as a consequence of emotional suffering, and were also related to traumatic situations. Fami- ly problems category was associated to personal group concerns, particularly their families. And the last category highlighted how the women suffering are interconnected with the favela's situation. Although these categories were described separately, the narratives carried complex patterns integrating physical and emotional suffering with the problems in their families and community.

Especially important was their description about personal suffering and how they cope with local rules in order to adapt their lives to what was possible ${ }^{42}$. For example, suffering was manifested linking personal and local problems to physical symptoms such as headaches, stomachaches, insomnia and blood pressure:

Sometimes I came to the Unit with a huge headache. So, she asks me (referring to the nurse) what is happening. Sometimes, it is a domestic problem, and I will tell you mam, I am not the kind of person that talk about my life to other people, I keep to myself. [...] I do not talk to anyone because it is difficult to find someone in this world that you can trust. So you talk to someone that share things about your life, even things that you did not say, so this is dull and I prefer not to say anything. (Orchid)

Furthermore, their suffering narratives demonstrated also emotional symptoms.

When I lost my son, he was 18 years old. I was very ... It was very bad for me. [...] I've..., I've felt like staying the whole day lying down, doing nothing. (Tulip)

The quotes indicated how violence has been forbidding these women to share their suffering. An internal conflict is presented: while talking could be helpful, it is also very painful to talk about these problems, which contents cannot be shared by local rules. This underlines how important are the coping abilities of these women to deal with their context ${ }^{28}$.

Descriptions associating favela's rules and suffering in an explicit way were also found:

$I$ went to get my grandson in the middle of shooting. And all this has worsen my health and I'm ... not a hundred per cent. But I'm looking for various ways to recover (This patient has also severe heart problems). (Daisy)

Once again another quote about the tension caused by the police presence inside the favela indicated the link between suffering and community rules:

Very scared, I was very afraid, any shot I heard... Even today, with the police in the community, I am still afraid, I am still nervous. I do not know, I am very afraid of being disturbed by them. (Heather) 
A study of Rio's favela demonstrated the link between the submission of vulnerable people living in favelas to gangs and security forces and the lack of systematic access to the health-care system $^{36}$. Thus, considering the coercive presence of weapons, this idea reinforced the power of the silence law as an implicit rule of communication as well as the use of personal resilience ${ }^{28}$ in order to survive ${ }^{43}$.

\section{Help Seeking Categories}

Help-seeking narratives highlighted issues about access and the therapeutic itinerary. The sub-categories detected were: health services, community solutions and self-help.

Health services category was divided in two: inside the community, when narratives referred to the FHS team's and outside, when they described access to other health unities such as specialised services. Community solutions category evidenced how they seek help in local resources as religious institutions, besides search for the local drug dealer's support. Self-help category was identified when they were conscious of their suffering and wanted a discrete and safe way to take care of themselves. Furthermore, help seeking categories underlined that they considered previous relationship quality before sharing an emotional suffering, including trust as a core component for accepting help ${ }^{32}$. A trustful relationship is fundamental and based on local context comprehension.

In the health services category narratives suggested that the doctor not being one from the community is a barrier:

I thought I have never complained about my situation, do you understand? I think in my mind... in my mind I think that the doctor is a person from outside, and he has nothing to do with my problem. [...] But I think it is like that, nobody has anything to do with my problems. I must handle the hot potato. (Violet)

In contrast, although they consider the FHS unit as a place for receiving care of their general health problems, including medication and vaccines, women emphasised barriers to talk about their emotional problems due to doctors' overload and length of the consultation:

[...] I am coming here (referring the health Unit) because I have diabetes, so, I come here, take my medicines, I verify my blood pressure, my sugar, everything here [...] And the doctor is looking after all people there, poor doctor, [...] You need to have a mind, you know, to be able to take care of different health problems and in her case she is only a general practitioner. (Rose)
Narratives about comprehension of care offer may affected negatively the trust in the FHS team, emphasizing how important was relationship recognised as a good and stable one for these woman to accept care ${ }^{44}$. For example, when they mentioned their relationship with the $\mathrm{CHW}$ that lives in the community and is an important link between these women and FHS Unit:

She is CHW. She is always at my house, when she goes to visit people there, she always knocks at the door to know how am I going on, do you know what I mean? (Palm)

Hence, CHW's role is recognised as a part of the community and a health professional that gives health information and facilitates the access of these women to the Unit.

Who has been helping me here a lot was my $\mathrm{CHW}$, the first-one was Flower. She helped me with my personal contraceptive planning, which included injections and later a chirurgic intervention for no longer been able to have children. (Orchid)

Additionally, the high turnover of FD is a point frequently associated with lack of trust and an important fail in the continuity of care, both tenets of FHS:

I know the CHW name [...] The doctor's name I don't know because it was my first consultation with her, she is new here, and I don't know her. (Angelica)

The lack of trust also arises from the fact that the same doctor consults other family members:

It is a place you cannot be commenting on your things. Everyone will know. [...]. Once my brother and I were treating with the same FD. [...] I knew that she had told him (something). Then that hurt me ... (Lily)

These quotations strengthened the association between trust and continuity of care, which was a problem related to high FD turnover:

Health services category was also related to places outside the community where help for emotional problems was sought, such as specialised services:

"[...] This psychologist was her colleague (mentioning the employer, who had indicated this professional). [...] I talked a lot with her, so this conversation helped me a lot, especially with my head. (Jessamine).

Bearing in mind the patients' barriers to discuss mental health suffering with FDs, the quote revealed that the women preferred to receive care for their suffering outside the community. It seems that this happens due to internal favela's rules, such as the "silence law", where no one can speak about certain local issues. 
Additionally, their comprehension about what is happening to them involves body and mind division. The analysis detected that these women looked for relief of associated physical symptoms when searching for a doctor:

I explained that I have been taking Benzodiazepines, but has not... but has not been working. So, the doctor prescribed an anti-allergic... (Acacia)

This underlined how they recognised that medication helps with their suffering in moments where the body did not answer as they wanted. Physical symptoms such as headache, insomnia and pain disturbed their lives routine. On the other hand, this quote suggested FD's difficulties to prescribe an effective medication:

The doctor was taking care of me... I do not go to the doctor today nowadays, but I have gone when I felt these things, I have gone to the doctor, he prescribed a medicine to everything and talked with me. (Jessamine)

That quote emphasises when the doctor combines medication prescription with conversation as a better way to take care and to relief CMD symptoms. This reveals that, when this composition makes sense to a patient, it is a clue to overleap the barriers in help seeking. Moreover, interviewees described individual and groups interventions organised by MHMS actions as safe spaces to share their emotional problems:

I have been taking the same medicines that Dr. Tree prescribed, that is a Benzodiazepine, there was another one that I forgot it. (Heather)

Because when I am in the group I fell better... I fell well. But when the group finished, and we (mentioning the group of women) went to our houses, it was as if everything come back... everything that was happening before. (Rose)

In both cases, data indicates trust and a sense of safety as keys to these women to accept the treatment. Theoretical references about accessibility in communities linked that to safe social spaces $^{45}$. Moreover, in this author transcultural perspective this quotation demonstrates how important groups are, not only to relieve emotional suffering but also to strengthen alliances and social relationships suggesting the creation of a "receptive social environment" empowers the voice of local groups to express needs and demands ${ }^{45}$.

Community solutions category emphasised that interviewees feel powerless to face these problems involving violence and drugs. For instance, when a woman contacted the drug dealers to help her to reprimand her violent and jealous partner.

I became depressed, so I could support no more [referring to conflicts with her partner], and then
I went to talk to the kids (local drug dealers) [...]. So he stopped for a while [...] I cannot call the police, I live in the community [...] then, as I said I'm sad, they scolded him and he stopped (referring to jealous partner). (Rose)

This revealed that she was sought help using favela's rules to relief some personal pressure. In this case, it is known that drug dealers act as a sort of community leaders and do not allow domestic violence.

The narratives also underlined how religious institutions were considered as one type of Community solutions for them:

I will try to read the Bible, when I have a lot of things (mentioning her problems). I look for... I turn on the radio on an Evangelic radio... (Pansy)

Especially noteworthy was how church could offer access to a health professional as a way to deal with suffering.

[...] our church has several doctors there and also it has a psychologist, because I have just talked to them, right? (Pansy)

Women's narratives revealed that they often find support in religious institutions. In the community these seem to be a possible place to take care of their problems:

When I was felling something, I ran away, I left everything and I went to church. [...] now I have been away from there for some months because shooting have been happening in my way, which makes me scary to go down to the church at night. But my refuge, when I was nervous, was going to Church, because I started to pray, and I delivered my problems to God, and asked for strength. (Violet)

The last category Self-help accentuated trust as a condition for help seeking. This suggests that the therapeutic itinerary may look ways for to avoid community problems, gossips, as well as a confrontation between their personal life and community rules.

I will not seek any psychologist to be knowing of my life, I will not be talking about my life to anyone. [...] I'm going there inside the park, and talk there with the trees there. [...] (Pansy)

Because it is difficult to involve other people in your problem. The problem is yours. There are things that only you can solve, nobody else, can you understand? (Marigold)

The narratives demonstrate concrete self-help examples to cope with their feelings of isolation and to be better adapted to their context. The resilience expressed might be the answer to the preference for personal solutions rather than professional approaches as suggested Dowrick et al. ${ }^{28}$. 
Help seeking categories demonstrate how these women have experienced their suffering and balanced different aspects such as community resources, local violence problems, CMD symptoms and the search for security and trust.

Why, when and with whom share emotional problems in Rio's favelas context?

The difficulties to engage an effective 'talk' with doctors were initially understood as a lack of readiness to seek help, its development pointed out how these women have been dealing with this violent context being resilient and creative.

The more resilient these women are, the more difficult is for them to spend their time to seek for help with health services, and consequently to talk with someone. Otherwise, their coping capacity has facilitated them to face their routine, surviving and adapting to the circumstances of an unstable ambient.

Another study with underserved CMD patients helped to clarify why they did not tend to consult a general practitioner ${ }^{46}$ and have a negative perception of offer of health care due to a weak doctor-patient relationship ${ }^{46}$. Besides the medical turnover, this study indicates that to establish a trustful relationship is important that health professionals understand cultural and individual aspects of their suffering. In general these experiences did not match priorities implicit in treatment CMD protocols ${ }^{47}$, however this help to develop alternatives to guarantee adherence and continuity of care.

Theoretical reference underlined the impacts of context, culture and local survival strategies on peoples' responses to adversity and illness and suggested a conceptualisation of community mental health competence, defined as the ability of community members to work collectively to facilitate more effective prevention, care, treatment and advocacy. This perspective emphasised the relevance of facilitating partnerships and critical thinking to produce a safe space for the "voice" of vulnerable communities. The group is a way to recognise communities' needs and empower them ${ }^{32}$. A literature review about trust, choice and empowerment found evidences demonstrating the role of continuity of care as essential to trust. This author highlighted empowerment as a collective outcome rather than an individual on $e^{48}$.

Summarising this study found that:

1. Women's suffering is commonly associated with favela's context, concerning vulnerabilities such as gender, low income and family status, and particularly with a lack of physical and psychological security for them and their families.

2. While trust is a core dispositive for these women to adhere to any health intervention, favela's rules forbids people to talk about their internal problems to an outsider, which may difficult health access. Additionally, this is prominent when the unit has problems such as high turnover and FD's overload. Otherwise, safety spaces to talk and access to medication are aspects that approximate FHS team and this population.

3. The therapeutic itinerary respects the community rules.

Strengths of this study were the contribution to the literature of primary mental health care in Latin America, highlighting the patients' perspectives of these processes. Only a qualitative study could demonstrate this type of result, reinforcing its importance in health research. The limitations include the small size of the sample and the fact that all interviewees come from the same community. Another limitation was that although the interviewees were women, gender issue were not considered in the analytical framework, which was focused on access to treatment. We consider that other studies should explore these aspects, contrasting different perspectives from women, health professionals and theoretical references.

This paper contributes for the facilitation of access and planning of tailored for Primary Mental Health Care interventions and vulnerable places. Development of trust, stability of health professionals inside the community, a better comprehension of social and cultural components of emotional suffering and the implementation of collective actions (groups) for support and empowerment came out as essential aspects in primary mental health care in Brazil.

\section{Conclusions}

This study about anxious and depressed women in Rio's favelas reveals how important is to understand the complex connections among clinical, social and cultural context to implement primary mental health care interventions.

Firstly, women's experiences revealed how the presence of constant violence has influenced their suffering. Help-seeking category revealed important itinerary therapeutic aspects where these women search available support to relive their suffering. Although the health services were described as important references, their narratives emphasised how favela's rules were deter- 
minant to their emotional suffering communication patterns, which came out as coping abilities.

Summing up, these categories highlighted potential barriers and facilitators in the relationship between these women and their FHS teams, pointing out that in order to accept this care offer, trust is a core factor and must be built considering not only medical evidences and anxiety and depression symptoms but also cultural and social factors.

\section{Collaborations}

K Athié took part in the construction of the research project, literature review, design of data analysis methodology, data analysis, structuring the article and writing the final version. C Dowrick took part in the literature review, design of data analysis methodology, data analysis, structuring the article and writing the final version. ALA Menezes took part in the construction of the research project, data collection, structuring the article and writing. L Cruz took part in the construction of the research project and data collection. AC Lima took part in the construction of the research project and data collection. PGG Delgado took part in the construction of the research project, literature review and data analysis methodology. C Favoreto took part in the construction of the research project, literature review and data analysis methodology. S Fortes took part in the construction of the research project, literature review, design of data analysis methodology, data analysis, structuring the article and writing the final version.

\section{References}

1. Kovandžić M, Chew-Graham C, Reeve J, Edwards S, Peters S, Edge D, Aseem S, Gask L, Dowrick C. Access to primary mental health care for hard-to-reach groups: From "silent suffering" to "making it work". Soc Sci Med 2011; 72(5):763-772.

2. Knowles SE, Chew-Graham C, Coupe N, Adeyemi I, Keyworth C, Thampy H, Coventry PA. Better together? a naturalistic qualitative study of inter-professional working in collaborative care for co-morbid depression and physical health problems. Implement Sci 2013; $8: 110$.

3. Archer J, Bower P, Gilbody S, Lovell K, Richards D, Gask L, Dickens C, Coventry P. Collaborative care for depression and anxiety problems. Cochrane database Syst Rev 2012; 10:CD006525.

4. Harkness E, Macdonald W, Valderas J, Coventry P, Gask L, Bower. Identifying psychosocial interventions that improve both physical and mental health in patients with diabetes: A systematic review and meta-analysis. Diabetes Care 2010; 33(4):926-930.

5. Ivbijaro GO, Enum Y, Khan AA, Lam SS, Gabzdyl A. Collaborative Care: Models for Treatment of Patients with Complex Medical-Psychiatric Conditions. Curr Psychiatry Rep 2014; 16(11):506.

6. Fortes S, Lopes CS, Villano LA, Campos MR, Gonçalves DA, Mari JJ. Common mental disorders in Petrópolis-RJ: a challenge to integrate mental health into primary care strategies. Rev Bras Psiquiatr 2011; 33(2):150-156.

7. Patel V, Araya R, de Lima M, Ludermir A, Todd C. Women, poverty and common mental disorders in four restructuring societies. Soc Sci Med 1999; 49(11):14611471.
8. Lancet Global Mental Health Group, Chisholm D, Flisher AJ, Lund C, Patel V, Saxena S, Thornicroft G, Tomlinson M. Scale up services for mental disorders: a call for action. Lancet 2007; 370(9594):1241-1252.

9. Hock RS, Or F, Kolappa K, Burkey MD, Surkan PJ, Eaton WW. A new resolution for global mental health. Lancet 2012; 379(9824):1367-1368.

10. Araya R, Alvarado R, Sepúlveda R, Rojas G. Lessons from scaling up a depression treatment program in primary care in Chile. Rev Panam Salud Publica 2012; 32(3):234-240.

11. Archer J, Bower P, Gilbody S, Lovell K, Richards D, Gask L, Dickens C, Coventry P. Collaborative care for depression and anxiety problems (Review). Cochrane Database Syst Rev 2012; 10:CD006525.

12. Lund C, Tomlinson M, De Silva M, Fekadu A, Shidhaye R, Jordans M, Petersen I, Bhana A, Kigozi F, Prince M, Thornicroft G, Hanlon C, Kakuma R, McDaid D, Saxena S, Chisholm D, Raja S, Kippen-Wood S, Honikman S, Fairall L, Patel V. PRIME: A Programme to Reduce the Treatment Gap for Mental Disorders in Five Low- and Middle-Income Countries. PLoS Med 2012; 9(12):e1001359.

13. Coventry P, Lovell K, Dickens C, Bower P, Chew-Graham C, McElvenny D, Hann M, Cherrington A, Garrett C, Gibbons CJ, Baguley C, Roughley K, Adeyemi I, Reeves D, Waheed W, Gask L. Integrated primary care for patients with mental and physical multimorbidity: cluster randomised controlled trial of collaborative care for patients with depression comorbid with diabetes or cardiovascular disease. BMJ 2015; 350:h638.

14. World Health Organization (WHO). Mental Health GAP intervention guide. Geneva: WHO; 2014. 
15. Chwastiak L, Vanderlip E, Katon W. Treating complexity: Collaborative care for multiple chronic conditions. Int Rev Psychiatry 2014; 26(6):638-647.

16. Patel V, Weiss HA, Chowdhary N, Naik S, Pednekar S, Chatterjee S, Bhat B, Araya R, King M, Simon G, Verdeli $\mathrm{H}$, Kirkwood BR. Lay health worker led intervention for depressive and anxiety disorders in India: impact on clinical and disability outcomes over 12 months. $\mathrm{Br}$ J Psychiatry 2011; 199(6):459-466.

17. Patel V, Weiss HA, Chowdhary N, Naik S, Pednekar S, Chatterjee S, De Silva MJ, Bhat B, Araya R, King M, Simon G, Verdeli H, Kirkwood BR. Effectiveness of an intervention led by lay health counsellors for depressive and anxiety disorders in primary care in Goa, India (MANAS): a cluster randomised controlled trial. Lancet 2010; 376(9758):2086-2095.

18. Prins MA, Verhaak PF, Bensing JM, van der Meer K. Health beliefs and perceived need for mental health care of anxiety and depression-The patients' perspective explored. Clin Psychol Rev 2008; 28(6):1038-1058.

19. Cooper LA, Brown C, Vu HT, Palenchar DR, Gonzales JJ, Ford DE, Powe NR. Primary care patients' opinions regarding the importance of various aspects of care for depression. Gen Hosp Psychiatry 2000; 22(3):163-173.

20. Aujoulat I, Luminet O, Deccache A. The perspective of patients on their experience of powerlessness. Qual Health Res 2007; 17(6):772-785.

21. van Grieken RA, Kirkenier AC, Koeter MW, Nabitz UW, Schene AH. Patients' perspective on self-management in the recovery from depression. Health Expect 2013; 18(5):1339-1348.

22. Jesmin S, Thind A, Sarma S. Does team-based primary health care improve patients' perception of outcomes? Evidence from the 2007-08 Canadian Survey of Experiences with Primary Health. Health Policy 2012; 105(1):71-83.

23. Cox WTL, Abramson LY, Devine PG, Hollon SD. Stereotypes, Prejudice, and Depression: The Integrated Perspective. Perspect Psychol Sci 2012; 7(5):427-449.

24. Saxena S, Thornicroft G, Knapp M, Whiteford H. Resources for mental health: scarcity, inequity, and inefficiency. Lancet 2007; 370(9590):878-889

25. Gensichen J, Guethlin C, Sarmand N, Sivakumaran D, Jäger C, Mergenthal K, Gerlach FM, Petersen JJ. Patients' perspectives on depression case management in general practice - A qualitative study. Patient Educ Couns 2011; 86(1):114-119.

26. Delor F, Hubert M. Revisiting the concept of "vulnerability”. Soc Sci Med 2000; 50(11):1557-1570.

27. Najar AL, Campos MR. Social inequalities and administration in health: methodology of selection of urban areas seeking to the decrease of the partner-space inequalities in metropolitan areas. Cien Saude Colet 2003; 8(2):471-478.

28. Dowrick C, Kokanovic R, Hegarty K, Griffiths F, Gunn $\mathrm{J}$. Resilience and depression: perspectives from primary care. Health (London) 2008; 12(4):439-452.

29. Harzheim E, Lima KM, Hauser L. Pesquisa avaliativa sobre aspectos de implantação, estrutura, processo e resultados das clinicas da família na cidade do Rio de Janeiro. Porto Alegre: UFRGS; 2013.

30. James Macinko DP. Brazil's Family Health Strategy Delivering Community-Based Primary Care in a Universal Health System. 2015.

31. Malagón-Oviedo RA, Czeresnia D. O conceito de vulnerabilidade e seu caráter biossocial. Interface (Botucatu) 2015; 79(4):613-639.
32. Hall MA, Dugan E, Zheng B, Mishra AK. Trust in physicians and medical institutions: what is it, can it be measured, and does it matter? Milbank Q 2001; 79(4):613-639.

33. Boardman F, Griffiths F, Kokanovic R, Potiriadis M, Dowrick C, Gunn J. Resilience as a response to the stigma of depression: A mixed methods analysis. J Affect Disord 2011; 135(1-3):267-276.

34. Levinson Miller C, Druss BG, Dombrowski EA, Rosenheck RA. Barriers to primary medical care among patients at a community mental health center. Psychiatr Serv 2003; 54(8):1158-1160.

35. Lamb J, Dowrick C, Burroughs H, Beatty S, Edwards S Bristow K, Clarke P, Hammond J, Waheed W, Gabbay M, Gask L. Community Engagement in a complex intervention to improve access to primary mental health care for hard-to-reach groups. Health Expect 2014 18(6):2865-2879.

36. Lamb J, Bower P, Rogers A, Dowrick C, Gask L. Access to mental health in primary care: A qualitative meta-synthesis of evidence from the experience of people from "hard to reach" groups. Health (London) 2012; 16(1):76-104.

37. Kadam UT, Croft P, McLeod J, Hutchinson M. A qualitative study of patients' views on anxiety and depression. Br J Gen Pract 2001; 51(466):375-380.

38. Snape D, Spencer L. The foundation of qualitative research. In: Ritchie J, Lewis J, editors. Qualitative research practice: A guide for social science students and researchers. London: Sage; 2003. p. 2-12.

39. Thomas J, Harden A. Methods for the thematic synthesis of qualitative research in systematic reviews. $B M C$ Med Res Methodol 2008; 8:45.

40. Patel V. Mental health in low- and middle-income countries. Br Med Bull 2007; 81-82:81-96.

41. Thomas DR. A General Inductive Approach for Analyzing Qualitative Evaluation Data. Am J Eval 2006; 27(2):237-246.

42. Rogers A, Oliver D, Bower P, Lovell K, Richards D. Peoples' understandings of a primary care-based mental health self-help clinic. Patient Educ Couns 2004; 53(1):41-46

43. Devi S. Innovation and education improve health in Rio's favelas. Lancet 2010; 376(9735):83-84.

44. Rondet C, Parizot I, Cadwallader JS, Lebas J, Chauvin P. Why underserved patients do not consult their general practitioner for depression: results of a qualitative and a quantitative survey at a free outpatient clinic in Paris, France. BMC Fam Pract 2015; 16:57.

45. Campbell C, Burgess R. The role of communities in ad vancing the goals of the Movement for Global Mental Health. Transcult Psychiatry 2012; 49(3-4):379-395.

46. Karasz A, Watkins L. Conceptual models of treatment in depressed Hispanic patients. Ann Fam Med 2006; 4(6):527-533.

47. Laugharne R, Priebe S. Trust, choice and power in mental health: A literature review. Soc Psychiatry Psychiatr Epidemiol 2006; 41(11):843-852.

48. Sunkel C. Empowerment and partnership in mental health. Lancet 2012; 379(9812):201-202.

Artigo apresentado em 25/02/2016

Aprovado em 10/08/2016

Versão final apresentada em 12/08/2016 